\title{
Radiological abnormalities in temporal lobe epilepsy with clinicopathological correlations
}

\author{
R. L. NEWCOMBE ${ }^{1}$, S. H. SHAH ${ }^{2}$, \\ with the assistance of \\ R. D. Hoare and M. A. Falconer ${ }^{3}$ \\ From the Neurosurgical Unit of Guy's, Maudsley, and King's College Hospitals, London
}

SYNOPSIS In 73 patients with drug-resistant temporal lobe epilepsy submitted to an unilateral anterior temporal lobectomy the radiographs were studied to see if there were any correlation with the pathology subsequently found and with the outcome of the operation. A small middle cranial fossa, focal calcification, and temporal horn displacement are often better indices of the underlying pathology than temporal horn dilatation alone. In a small number of cases, however, radiological changes were seen on the side opposite to an unilateral EEG focus, thus suggesting bilateral disease.

There is now good evidence that epilepsy arising from the temporal lobe often has a structural basis rather than being idiopathic (Falconer $e t$ al., 1964; Falconer, 1969). The epileptogenic lesions are usually small and often in the region of Ammon's horn (hippocampus). The most frequent lesion is sclerosis of the hippocampus and neighbouring structures-mesial temporal sclerosis (Falconer et al., 1964; Margerison and Corsellis, 1966). Small hamartomas (Cavanagh, 1958; Falconer and Cavanagh, 1959), scars and infarcts, and non-specific gliosis without neuronal abnormalities are less commonly encountered. Rarely, other discrete lesions, such as small capillary angiomas and epidermoid cysts, may also occur.

Falconer and Taylor (1968) reported 100 consecutive patients in whom gross spaceoccupying lesions were excluded by neuroradiological studies, and who were submitted to an unilateral temporal lobectomy and followed up for two to 12 years. They related the clinical outcome to four groups of pathological substrates. Mesial temporal sclerosis (MTS) was present in half of these patients and the best results of

1 Present address: Dr R. L. Newcombe, Canberra Hospital, Acton, A.C.T. 2601, Australia.

2 Present address: Dr S. H. Shah, George Washington University Hospital, 901 Twenty-third Street N.W., Washington, D.C., U.S.A. 3 Reprint requests: Mr M. A. Falconer, Neurosurgical Unit, Maudsley Hospital, De Crespigny Park, London S.E.5. (Accepted 21 October 1974.) surgery were in this group. Hamartomas, which may be regarded as small developmental abnormalities, occurred in $22 \%$ of cases. They also had a good prognosis for relief of seizures, but were less likely to be associated with improvement in social adaptation. Miscellaneous scars and infarcts occurred in about $12 \%$ and the remainder had no specific neuronal pathology. A good prognosis after operation was less common in the latter two categories. These patients all had a predominantly unilateral electroencephalographic (EEG) spiking focus but no detailed consideration was given to the radiological findings in their study. The radiological investigations, therefore, have now been reviewed in an attempt to assess their value in identifying the site and nature of the pathological process. It was presumed before this review that a good therapeutic result meant that the correct temporal lobe had been resected, while a poor therapeutic result cast doubts on this, especially if it were shown that there were radiological abnormalities on the opposite side.

\section{METHOD}

Two of us (R.L.N. and S.H.S.) studied blind the plain skull films and lumbar pneumoencephalograms of 73 English-speaking patients from the series reported by Falconer and Taylor (1968). Neither the 279 
initial assessment and the cases were studied in random order. The two assessors had no prior knowledge of the individual patients in this seriesthe radiographs had previously been reported by R.D.H. and the operations performed by M.A.F. The remaining 27 patients of the earlier series were excluded because the radiographs were either no longer available or were incomplete. All patients were examined on a skull table with anode-film distance of 36 in $(90 \mathrm{~cm})$.

PLAIN SKULL RADIOGRAPHS In the plain skull films the following were recorded: (1) skull symmetry, with particular attention to vault thickness and hemiatrophy; (2) symmetry and size of the middle cranial fossae; (3) focal areas of abnormal calcification.

The size of the middle fossa was assessed as normal or small on the basal and half-axial views. Special emphasis was given to the radius of the curve of the anterior margin of the fossa as seen on the basal $\underset{\mathbb{D}}{Z}$ view and to the configuration of the floor of the fossa in the half-axial projection.

In the basal view, the middle fossa was regarded as small on one side if there was distinct asymmetry in 0 appearance without general skull asymmetry, taking into account the curve of the anterior part of the $\stackrel{3}{=}$ fossa and the difference in width of the skull base $\stackrel{0}{\overrightarrow{0}}$ between the midline and the inner table of the $s$ temporal part of the vault. A tracing of one side $\overrightarrow{\vec{F}}$ reversed to superimpose over the other side on the $\frac{?}{0}$ film assists in this assessment. In stating that a middle fossa was small we imply a relative difference be- $\frac{\bar{\sigma}}{\bar{\omega}}$ tween the two sides, not necessarily pathological.

The relative heights of the petrous ridge in the $\propto$ half-axial view, the degree of thickening of the is temporal part of the vaults, and the amount of $\vec{\circ}$ pneumatization of the temporal bone were also taken

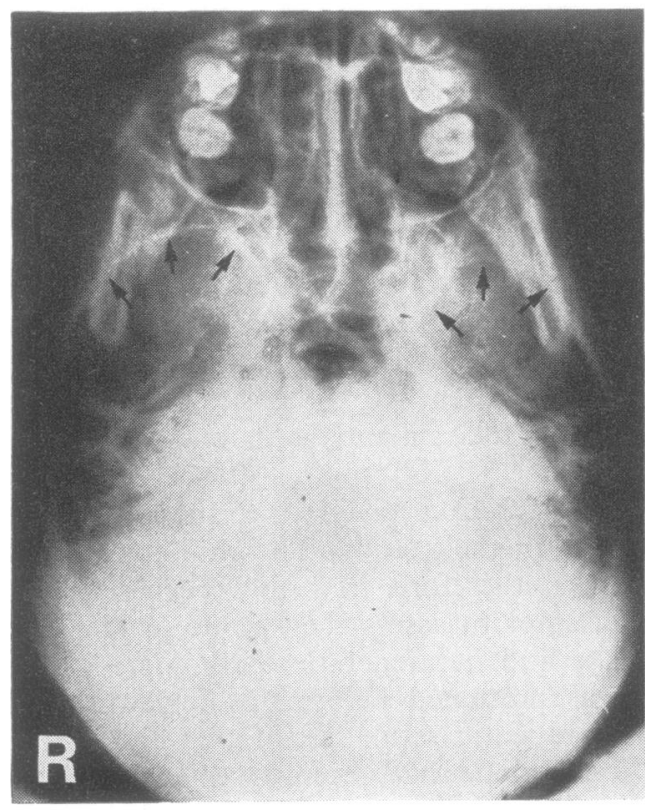

(a)

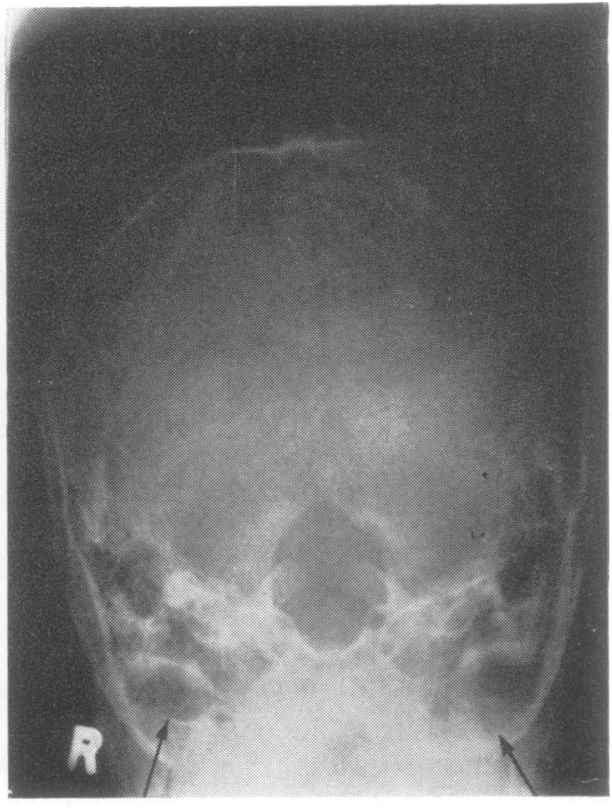

(b)

FIG. 1 Two marked examples of small middle cranial fossas. (a) Basal view showing small middle fossa on left side in a 14 year old girl with mesial temporal sclerosis, who was completely relieved by subsequent left temporal lobectomy. The curve of the sphenoidal ridge on each side is indicated by arrows. (b) Half axial view showing thick temporal vault on right side and shallow temporal fossa in an 11 year old boy with an atrophic temporal lobe with porencephaly. The difference in the floor of the middle fossa on the two sides is indicated by arrows, while the right petrous ridge is relatively higher than the left. The patient was improved by right temporal lobectomy. 
into consideration. Two marked examples of small middle fossa on one side are shown in Fig. 1.

ENCEPHALOGRAPHY The features assessed include: (1) the size and symmetry of the ventricular system as a whole; (2) the size, shape, and position of the temporal horn (Lindgren, 1947, 1948.)

The following measurements were made: (a) body of the lateral ventricle-transverse and diagonal width; (b) septum - caudate line; (c) width of third ventricle; (d) width of lateral cleft of temporal horn.

Separate assessments for the anterior horn and trigone of the lateral ventricles were made on the general appearances. The following measurements were accepted as the upper limits of normal ranges:

Third ventricular width: $9 \mathrm{~mm}$

(Robertson, 1959)

Transverse ventricular width: $45 \mathrm{~mm}$

(Davidoff and Dyke, 1946)

Diagonal width of lateral ventricle: $20 \mathrm{~mm}$

(Davies and Falconer, 1943)

Septum-caudate line: $14 \mathrm{~mm}$

(Troland et al., 1946)

Lateral cleft of temporal horn: $4 \mathrm{~mm}$

(Van Buren et al., 1956).

The width of the lateral cleft of the temporal horn was measured in the half-axial view where the cleft is narrowest just behind the flared tip of the horn. The presence or absence of an indentation of the lateral cleft by the collateral eminence was also noted. Whenever the lateral cleft measurements were more than $4 \mathrm{~mm}$ we considered the temporal horn to be dilated.

The findings were then correlated with the side of operation, the pathology of the resected temporal lobes, and the clinical outcome. Pathological lesions were grouped as mesial temporal sclerosis (MTS), hamartomas (HAM), miscellaneous lesions (MISC) such as scars and infarcts, and non-specific gliosis (NON-SP). Clinical outcome (for seizure relief only) was graded:

I Fit free postoperatively

II Marked improvement

III Partial improvement

IV No change

The mean age at operation was 26.1 years (range 11-46 years). There were 45 males and 28 females.

\section{RESULTS}

\section{A. RADIOLOGICAL FINDINGS AND LATERALITY}

Radiological abnormalities were present in 51 patients $(70 \%)$ (Table 1$)$. Unilateral abnormalities on plain skull radiography corresponded with the side chosen for operation in 28 of the total of 37 . On encephalography, unilateral abnormalities corresponded with the operated side in 29 of a total of 44 . The remainder showed bilateral changes, or changes on the nonoperated side only.

\section{TABLE 1}

RADIOLOGICAL FINDINGS IN TEMPORAL LOBE EPILEPSY*

\begin{tabular}{|c|c|c|c|}
\hline \multicolumn{2}{|l|}{ Skull radiography } & \multicolumn{2}{|l|}{ Encephalography } \\
\hline $\begin{array}{l}\text { Normal } \\
\text { Abnormal }\end{array}$ & $\begin{array}{l}36 \\
37\end{array}$ & $\begin{array}{l}\text { Normal } \\
\text { Abnormal }\end{array}$ & $\begin{array}{l}29 \\
44\end{array}$ \\
\hline Skull radiographic abnormalit & ties & Encephalographic abnorma & alities \\
\hline 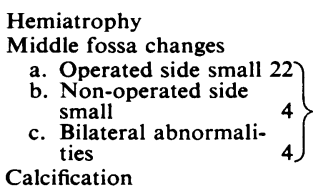 & $\begin{array}{r}30 \\
\quad 3\end{array}$ & $\begin{array}{l}\text { Atrophy } \\
\text { Hemiatrophy } \\
\text { Dilated temporal horn } \\
\text { a. Operated side } 2 \\
\text { b. Non-operated side } 1 \\
\text { c. Bilateral } \\
\text { Displacement of temporal } \\
\text { horn }\end{array}$ & $\left.\begin{array}{r}3 \\
2 \\
21 \\
10 \\
2\end{array}\right\} \begin{array}{r}33 \\
3\end{array}$ \\
\hline
\end{tabular}

$* N=73$. Skull radiographs and encephalogram both normal $=22$ $(30 \%)$.

\section{PLAIN SKULL RADIOGRAPHS}

HEMIATROPHY Eighteen cases had general skull asymmetry, within normal limits. Four had definite hemicranial atrophy and the side of hemiatrophy was the side of the operation in all four.

MIDDLE fOSSA CHANGeS 1. Unilateral Twentytwo patients were assessed as having a small middle fossa on one side. The middle fossa floor was small on the operated side in 12 instances. In some of these, other changes were also present, including a high petrous ridge (nine), thickening of the temporal vault (three), and excessive temporal air cells (two). Also on the operated side, a high petrous ridge alone was noted in seven, thickening of the temporal vault in one, and excessive pneumatization in two.

On the non-operated side (when the operated side was normal), we found two examples of small middle fossa floor in the basal view and two of high petrous ridge shown by the halfaxial and posteroanterior projections. 
2. Bilateral Bilateral changes which were detected included: (a) Two patients with thickened temporal vault and excessive pneumatization of equal degree on both sides; (b) two patients with a small middle fossa floor on the operated side but a high petrous ridge on the other side.

CALCIFICATION There were three patients with anterior temporal calcification (Fig. 3a). The calcified areas were $0.5-1 \mathrm{~cm}$ diameter and all were unilateral. All proved to be hamartomas.

\section{ENCEPHALOGRAPHIC FINDINGS}

ATROPHY AND HEMIATROPHY The bodies of the lateral ventricles were symmetrical in 45 cases and asymmetrical in 28 . In three patients there was symmetrical dilatation with other features sufficient to support a radiological diagnosis of mild cerebral atrophy. Of the asymmetrical cases, two had definite hemiatrophy and others had slight degrees of lateral ventricular enlargement in association with a more marked degree of temporal enlargement. (In two cases the anterior horn alone was enlarged on one side when the body was not, and the trigone was enlarged when the body was not in three cases. All these had temporal horn dilatation. There were no cysts, ventricular diverticula, or midline displacements of note.)

TEMPORAL HORN ABNORMALITIES Apart from the patients with cerebral atrophy or hemiatrophy, there were 33 patients with dilatation of one or both temporal horns. Two had bilateral enlargement and in these the remainder of the ventricular system was normal. In the 31 unilateral cases, there was some enlargement of the ipsilateral ventricle in $15(45 \%)$. The left temporal horn was more commonly dilated than the right.

In 10 patients, a dilated temporal horn was present on the non-operated side with a normal temporal horn on the side of resection. These films were reviewed a second time by one of us (S.H.S.) without access to the original interpretation and without any clinical or pathological data.

In one, the difference between the two sides was slight and the larger temporal horn may have been at the upper limit of normal range. In the other nine, the abnormality was confirmed.

Displacement with distortion of the temporal horn was seen in six instances, suggesting a hamartoma or sclerosis. These displacements involved only the anterior part of the temporal horn. The displacement was towards the midline in two, upwards and laterally in four.

The radiological demonstration of the collateral eminence of the temporal horn was studied. This, a normal anatomical structure of variable proportion, sometimes causes a demonstrable indentation on the inferolateral aspect of the temporal horn. It usually corresponds with the collateral fissure on the inferior aspect of the temporal lobe. In this series it was unilaterally prominent in 16 cases and in none was it prominent on both sides. In 12 patients with a prominent collateral eminence, the temporal horn was dilated on the same side. In four, the temporal horn on the same side was normal in size.

\section{B. PATHOLOGY}

In the 22 patients with both normal skull radio graphs and normal lumbar pneumoencephalo grams, focal pathology was subsequently founc at operation in all but two. The distribution was mesial temporal sclerosis $13(59 \%)$; hamartomas $4(18 \%)$; miscellaneous $3(14 \%)$; non-specific 2 $(9 \%)$.

These findings form a basis for comparison with those with abnormal radiographs. The pathology associated with the plain radiographic changes is shown in Table 2. Hemiatrophy occurred in MTS, hamartomas and non-specific gliosis. Mesial temporal sclerosis occurred in association with changes suggesting a small middle fossa on the same side in 12 cases and on the opposite side in three cases. All the calcified lesions were hamartomas.

The pathology associated with encephalographic abnormalities is shown in Table 3 . In atrophy and hemiatrophy, the histological findings were either MTS, or non-specific gliosis. There were positive associations $(\mathrm{P}<0.01)$ of mesial temporal sclerosis or non-specific pathology with temporal horn dilatation, and of $\mathcal{N}$ hamartomas with temporal horn displacement. Typical changes in MTS and hamartomas are illustrated in Figures 2 and 3. 

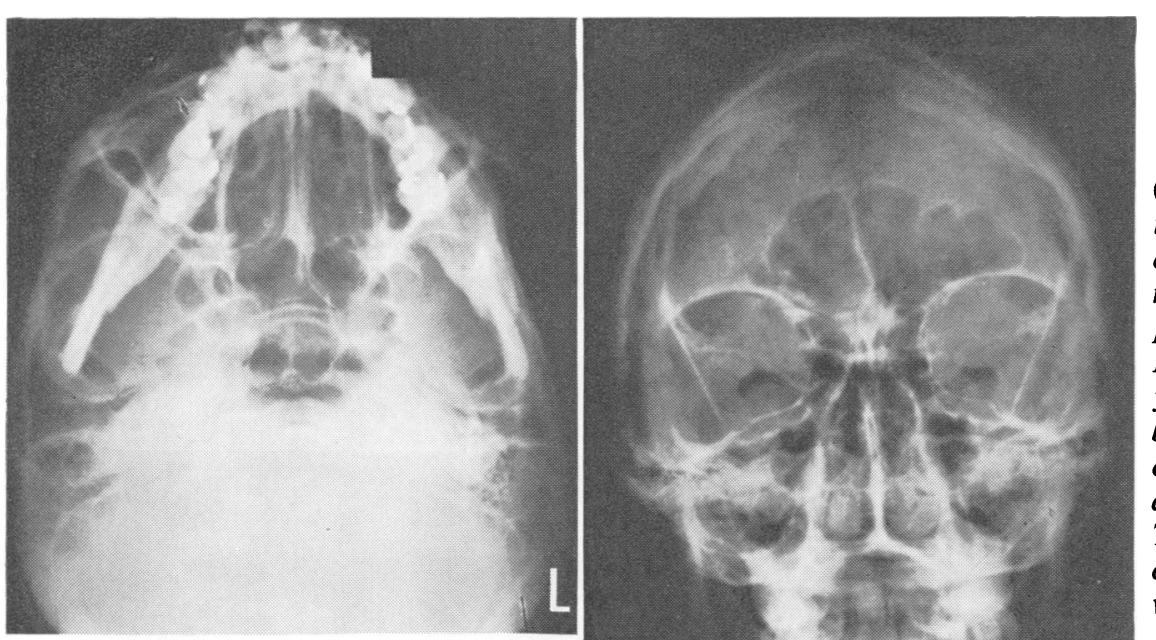

(b) Dilatation of left temporal horn (with elevation of petrous ridge). Anteroposterior view. Female, aged 19 years. Precipitate birth and infantile convulsions beginning at 3 months of age. The left middle cranial fossa floor was also small.

(a) Small middle cranial fossa (left side). Basal view. Female, aged 36 years. Infantile convulsions at 18 months.

(c) Dilated left temporal horn with appearance of smallness of the hippocampus compared with the other side (arrow). Anteroposterior view. Female, aged 18 years. Infantile convulsions after head injury at 2 years of age.

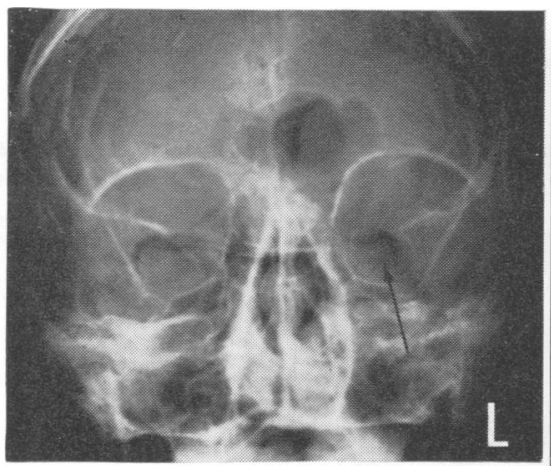

(d) Gross temporal lobe atrophy with dilated right temporal horn and small right hemicranium. Anteroposterior view. Female, aged 24 years. Convulsions at the age of 5 years associated with right temporal otogenic abscess.

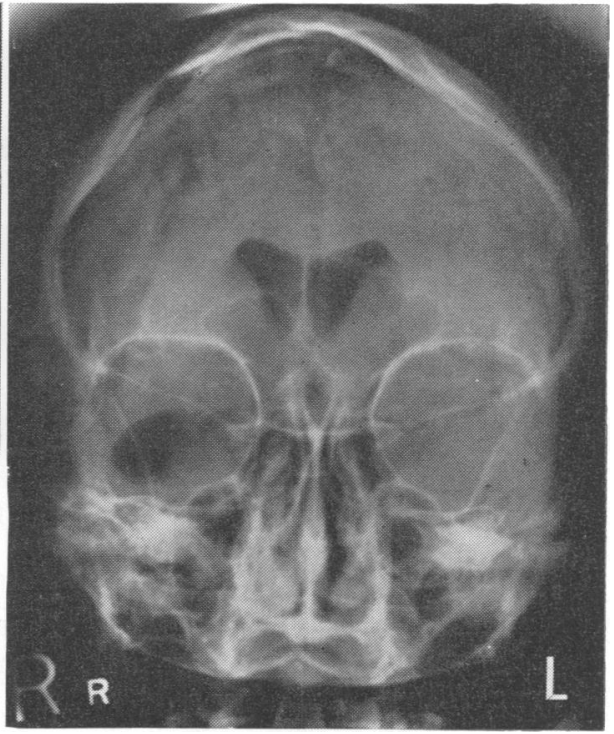

FIG. 2 Features of mesial temporal sclerosis in temporal lobe epilepsy. 

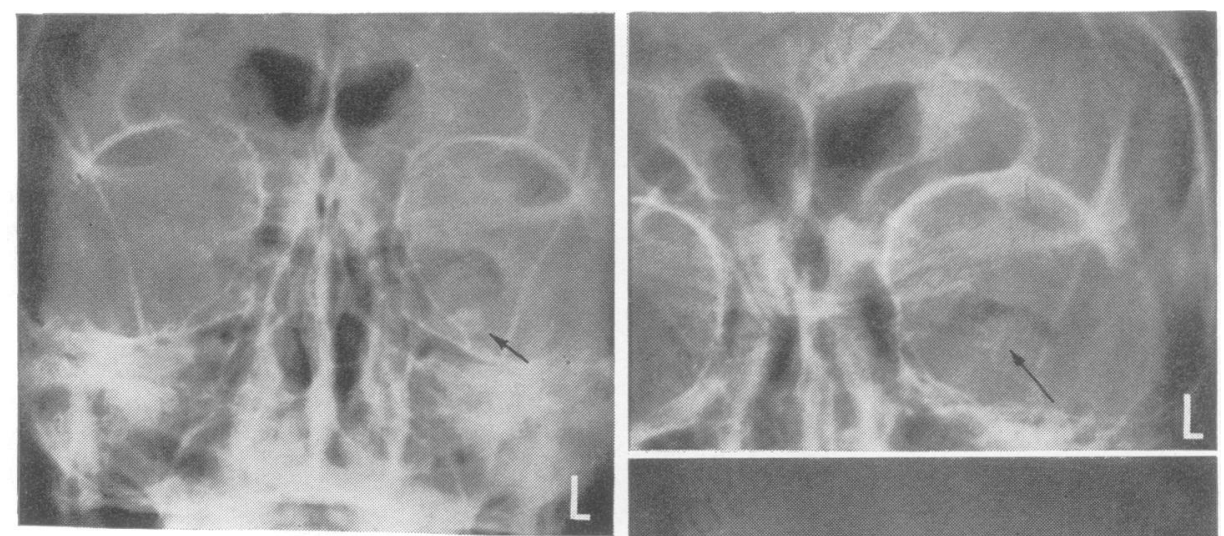

FIG. 3 Features of hamartomas in temporal lobe epilepsy. (a, top left) Calcified lesion (arrow) in medial part of left temporal lobe, elevating temporal horn. Associated small middle cranial fossa. Anteroposterior view. Male, aged 23 years. (b, top right) Hamartoma indenting hippocampal aspect of left temporal horn (arrow). Anteroposterior view. Male, aged 44 years. (c, bottom right) Lateral displacement of right temporal horn with indentation of hippocampal aspect (arrow). Half-axial view. Male, aged 19 years.

\section{CLINICAL OUTCOME}

In the radiologically normal group (22), the clinical outcome regarding seizure relief was graded as follows:

$$
\begin{aligned}
& \text { grade I } 12 \\
& \left.\begin{array}{rr}
\text { II } & 4 \\
\text { III } & 4 \\
\text { IV } & 2
\end{array}\right\} 6(27 \%(73 \%)
\end{aligned}
$$

In Table 4, the abnormalities found in plain radiographs of skull are related to clinical outcome. All the patients with calcified lesions (hamartomas) did well (outcome grades I and II). Of those with unilateral middle fossa changes on the operated side (mainly MTS or nonspecific pathology), there was no significant difference in outcome compared with the group with normal radiographs.

The relationship of encephalographic change to clinical outcome is shown in Table 5. Those

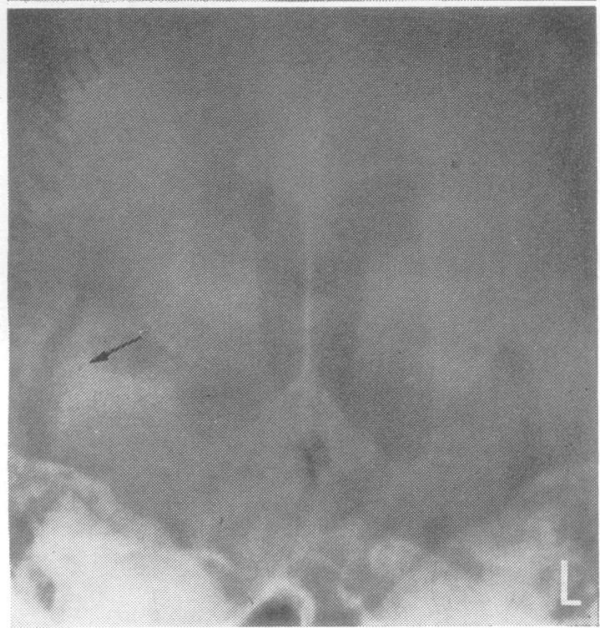

TABLE 2

CORRELATION OF PLAIN RADIOGRAPHS OF SKULL

\begin{tabular}{|c|c|c|c|c|c|}
\hline \multirow[t]{2}{*}{ Radiological findings } & \multirow{2}{*}{$\begin{array}{l}\text { Patients } \\
\text { (no.) }\end{array}$} & \multicolumn{4}{|c|}{ Pathology } \\
\hline & & $M T S$ & $H A M$ & MISC & $N O N-S P$ \\
\hline $\begin{array}{l}\text { Hemiatrophy } \\
\text { Small middle fossa }\end{array}$ & 4 & 2 & 1 & - & 1 \\
\hline Operated side & 22 & 12 & 1 & 2 & 7 \\
\hline Non-operated side & 4 & 3 & - & - & 1 \\
\hline Bilateral & 4 & 7 & - & - & - \\
\hline Calcification & 3 & 一 & 3 & - & - \\
\hline Normal & 36 & 18 & 5 & 3 & 10 \\
\hline
\end{tabular}
AND PATHOLOGY

with cerebral atrophy or hemiatrophy tended to have a poor outcome, while those with temporal horn displacement (mainly hamartoma) had a favourable one. There was no significant difference in outcome between those who had slight to 
TABLE 3

CORRELATION OF ENCEPHALOGRAPHIC CHANGES AND PATHOLOGY

\begin{tabular}{lccccc}
\hline Radiological findings & $\begin{array}{c}\text { Patients } \\
(\text { no. })\end{array}$ & \multicolumn{5}{c}{ Pathology } \\
\cline { 3 - 6 } & & MTS & HAM & MISC & NON-SP \\
\hline $\begin{array}{l}\text { Generalized atrophy } \\
\text { Hemiatrophy }\end{array}$ & 3 & 2 & - & - & 1 \\
$\begin{array}{l}\text { Dilated temporal horn } \\
\quad \text { Operated side }\end{array}$ & 21 & 1 & - & - & 1 \\
$\begin{array}{l}\text { Bilateral } \\
\text { Non-operated side }\end{array}$ & 12 & 1 & - & - & 5 \\
$\begin{array}{l}\text { Temporal horn dis- } \\
\text { placement }\end{array}$ & 10 & 4 & - & 1 & 5 \\
Normal & 6 & 2 & 3 & - & 1 \\
& 29 & 13 & 6 & 4 & 6 \\
\hline
\end{tabular}

TABLE 4

CORRELATION OF PLAIN RADIOGRAPHS OF SKULL AND CLINICAL OUTCOME

\begin{tabular}{lrrrrrr}
\hline Radiological findings & $\begin{array}{c}\text { Patients } \\
\text { (no.) }\end{array}$ & \multicolumn{4}{c}{ Clinical } & outcome (grade) \\
\cline { 3 - 7 } & & & $I$ & $I I$ & $I I I$ & IV \\
\hline Hemiatrophy & 4 & 2 & - & 2 & - \\
Small middle fossa & 22 & 10 & 7 & 3 & 2 \\
$\quad$ Operated side & 4 & 1 & 1 & - & 2 \\
$\quad$ Non-operated side & 4 & 2 & 2 & - & - \\
$\quad$ Bilateral & 3 & 2 & 1 & - & - \\
Calcification & 36 & 16 & 7 & 6 & 7 \\
Normal & & & & & & \\
\hline
\end{tabular}

TABLE 5

ENCEPHALOGRAPHIC CHANGES AND CLINICAL OUTCOME

\begin{tabular}{|c|c|c|c|c|c|}
\hline \multirow[t]{2}{*}{ Radiological findings } & \multirow{2}{*}{$\begin{array}{l}\text { Patients } \\
\text { (no.) }\end{array}$} & \multicolumn{4}{|c|}{ Clinical outcome (grade) } \\
\hline & & $I$ & II & III & $I V$ \\
\hline Generalized atrophy & 3 & - & 1 & 1 & 1 \\
\hline Hemiatrophy & 2 & - & - & 2 & - \\
\hline \multicolumn{6}{|l|}{ Dilated temporal horn } \\
\hline Operated side & 21 & 8 & 7 & 5 & 1 \\
\hline Non-operated side & 10 & 4 & 2 & - & 4 \\
\hline Bilateral & 2 & 1 & - & - & 1 \\
\hline Temporal horn displacement & 6 & 3 & 2 & - & 1 \\
\hline Normal encephalogram & 29 & 17 & 6 & 3 & 3 \\
\hline
\end{tabular}

moderate dilatation of the temporal horns on the operated side and those who were normal radiologically.

\section{DISCUSSION}

There has been little comment in the literature concerning radiological abnormalities in tem- poral lobe epilepsy, perhaps because of the problems involved in assessment. The changes are often subtle and largely determined by comparison between the two sides. In this paper we have not regarded minimal asymmetry of the temporal horns as an indication of pathology. Some instances of possible bilateral skull or encephalographic change may have gone undetected. In the absence of plain film changes we feel we cannot diagnose a lesion on the basis of a small temporal horn, as shown on encephalography, although it is well known that some cases of mesial temporal sclerosis with an atrophic hippocampus are associated with a small temporal horn as seen in the half axial view.

The abnormalities found were (a) atrophic changes associated with a small temporal lobethat is, a small middle fossa with or without temporal horn dilatation; (b) changes of small discrete space-occupying lesions; or (c) calcification.

ATROPHIC CHANGES Cerebral atrophy or hemiatrophy was present in a few patients (Table 3). It was hoped preoperatively that the anterior temporal lesions found in these patients were responsible for epileptic attacks and that improvement would follow anterior temporal lobectomy, even though disease was clearly more widespread. Our findings suggest that a good outcome (grades I and II) is unlikely in such patients, although an exception to this general finding has since been observed.

Middle fossa changes are often less obvious than those of hemiatrophy, but sometimes they are striking. A small temporal lobe is a common finding at operation. Falconer and Cavanagh (1959) have suggested that a small middle cranial fossa may be evidence of such lesions as mesial temporal sclerosis or glial hamartomas, and our findings bear this out. Another index of a small temporal lobe is the height of the Sylvian vessels above the floor of the middle fossa (unpublished observations), but angiography is not justified for this alone and was rarely performed in the present series.

In plain radiographs of skull, an atrophic temporal lobe may be indicated by: (1) small middle fossa floor area; (2) a relatively high petrous ridge, indicating a shallow fossa; and (3) 
thickening of temporal part of the vault and possibly excessive pneumatization.

Atrophic changes were sometimes bilateral suggesting bilateral disease. Eleven patients had unilateral abnormalities on the side opposite to the operated side. One of these had an anteromedial temporal infarct on the operated side and the radiological diagnosis was probably erroneous-the dilated horn being, in fact, within the normal range of variation. In four, there was mesial temporal sclerosis on the radiologically normal (resected) side and the outcome was good. These may have had bilateral MTS, which was epileptogenic only, or principally, on the operated side. In the remaining six cases, non-specific pathological changes were found, with a poor outcome in five (grades III and IV). In the latter it might be asked whether an operation on the radiologically abnormal side would have been more beneficial. Review of the clinical records shows, however, that the fit pattern and dominant EEG changes were on the operated side, though in all six cases there were bilateral EEG abnormalities which were often multifocal. It is probable in these cases that disease was diffuse or bilateral. It therefore seems unlikely that operation on the side of the radiological changes would have led to a better result.

The establishment of laterality of an epileptic lesion may be particularly difficult in children (Falconer, 1972). Radiological changes may prove to be a guide, but the experience of this series, which is composed mainly of adults, shows that caution is required in the case of atrophic changes. The observation of calcification or of temporal horn displacement is of greater value.

CALCIFICATION Calcified lesions are rare. Epileptogenic calcified lesions in the anterior temporal region, usually due to hamartomas, have been noted previously by several authors, including Geyelin and Penfield (1929), Alexander (1953), Falconer and Pond (1953), Kennedy and Hill (1958), Falconer and Kennedy (1961), and Falconer (1966). A calcified mass without distortion of the temporal horn was illustrated by Falconer (1970) and an instance of focal bilateral hippocampal calcification and café-aulait spots was recorded by Williams (1972). Sometimes, calcification may direct attention to a lesion at some distance from the electroencephalographic focus. Two cases of psychomotor epilepsy with anterior temporal spike? discharges were relieved by the excision of 0 occipital calcified lesions (Falconer et al., 1962). एo

In this paper we report three instances of oㅇ calcified hamartoma. Other cases of hamartoma showed displacement or distortion of the temporal horn, while the remainder were radiologically normal. All were benefited by surgery.

\section{CONCLUSIONS}

There would thus appear to be considerable value in such radiological studies in intractable $\overrightarrow{0}$ temporal lobe epilepsy. To some extent the $\overrightarrow{-}$ nature of the lesion may be predicted. Calcifica- $\vec{\omega}$ tion, a small middle cranial fossa, and displace- $-\frac{\widehat{J}}{\bar{z}}$ ment of the temporal horn are the most specific changes, while the presence or absence of $\dot{\omega}_{\infty}$ ventricular dilatation is less reliable since it does $\omega$ not distinguish MTS from non-specific glios unless the middle fossa is also small. In our more recent work we have used tomography of tie temporal horn, as have Fredy and Bories (1972

Considerable caution needs to be observed th the interpretation of radiological changes, paํำ공 ticularly if the clinical and electroencephako: $\overrightarrow{0}$ graphic pictures are at variance. The absence of radiological changes does not exclude an epileptogenic lesion with a well-defined focal histology.

\section{REFERENCES}

Alexander, W. S. (1953). Cerebral calcification epilepsy. $\overline{\overline{0}}$ Journal of Neurosurgery, 10, 69-73. Cavanagh, J. B. (1958). On certain small tumours encountered
in the temporal lobe. Brain, 81, 389-405.

Davidoff, L. M., and Dyke, C. G. (1946). The Normal Encephalogram. 2nd edn. Lea: Philadelphia.

Davies, H., and Falconer, M. A. (1943). Ventricular changes? after closed head injury. Journal of Neurology and Psychiatry, 6, 62-68.

Falconer, M. A. (1966). Problems in neurosurgery: temporal lobe epilepsy; the assessment of patients for surgical 3 treatment. Transactions of the Medical Society of London, 82, 111-126.

Falconer, M. A. (1969). The pathological subtrate of temporal lobe epilepsy. Guy's Hospital Reports, 47-60.

Falconer, M. A. (1970). Significance of surgery for temporal lobe epilepsy in childhood and adolescence. Journal of $\mathrm{N}$ Neurosurgery, 33, 233-252.

Falconer, M. A. (1972). Temporal lobe epilepsy in children $N$ and its surgical treatment. Medical Journal of Australia, 1, స్ 1117-1121. 
Falconer, M. A., and Cavanagh, J. B. (1959). Clinico-pathological considerations of temporal lobe epilepsy due to small focal lesions. Brain, 82, 483-504.

Falconer, M. A., Driver, M. V., and Serafetinides, E. A. (1962). Temporal lobe epilepsy due to distant lesions: two cases relieved by operation. Brain, 85, 521-534.

Falconer, M. A., and Kennedy, W. A. (1961). Epilepsy due to small focal temporal lesions with bilateral independent spike-discharging foci: a study of seven cases relieved by operation. Journal of Neurology, Neurosurgery, and Psychiatry, 24, 205-212.

Falconer, M. A., and Pond, D. A. (1953). Temporal lobe epilepsy with personality and behaviour disorders caused by an unusual calcifying lesion. Journal of Neurology, Neurosurgery, and Psychiatry, 16, 234-244.

Falconer, M. A., and Serafetinides, E. A. (1963). A follow-up study of surgery in temporal lobe epilepsy. Journal of Neurology, Neurosurgery, and Psychiatry, 26, 154.

Falconer, M. A., Serafetinides, E. A., and Corsellis, J. A. N. (1964). Etiology and pathogenesis of temporal lobe epilepsy. Archives of Neurology (Chic.), 10, 233-248.

Falconer, M. A., and Taylor, D. C. (1968). Surgical treatment of drug-resistant epilepsy due to mesial temporal sclerosis. Archives of Neurology (Chic.), 19, 353-361.

Fredy, D., and Bories, J. (1972). A tomographic study of the temporal horn. Neuroradiology, 4, 96-107.

Geyelin, H. R., and Penfield, W. (1929). Cerebral calcifica- tion epilepsy: endarteritis calcificans cerebri. Archives of Neurology (Chic.), 21, 1020.

Kennedy, W. A., and Hill, D. (1958). Surgical prognostic significance of the electroencephalographic prediction of Ammon's horn sclerosis in epileptics. Journal of Neurology, Neurosurgery, and Psychiatry, 21, 24-30.

Lindgren, E. (1947). The normal temporal horn and its deformities by tumours in the middle cranial fossa. Proceedings of the Royal Society of Medicine, 40, 859-862.

Lindgren, E. (1948). A pneumographic study of the temporal horn. Acta Radiologica, Suppl. 69, Stockholm.

Margerison, J. H., and Corsellis, J. A. N. (1966). Epilepsy and the temporal lobes; a clinical, encephalographic and neuropathology study of the brain in epilepsy, with particular reference to the temporal lobes. Brain, 89, 499-530.

Robertson, E. G. (1957). Pneumoencephalography. Blackwell: Oxford.

Troland, C. E., Baxter, D. H., and Schatzki, R. (1946). Observations on encephalographic findings in cerebral trauma. Journal of Neurosurgery, 5, 390-398.

Van Buren, J. M., Baldwin, M., and Alvord, E. C. Jr (1956). The temporal horn: its development, normal variations and changes associated with non-expanding epileptogenic lesions of the temporal lobe. Acta Radiologica, 46, 703-718.

Williams, J. E. (1972). Radiographic hippocampal calcifications. Neuroradiologica, 4, 159-161. 